\title{
"Uma voz contra a impunidade": uma análise sobre o contexto da campanha eleitoral do Coronel Bezerra à Assembleia Legislativa do Ceará
}

\author{
Antonio Sabino da Silva Neto', Leonardo Damasceno de Sá ${ }^{2}$ e \\ Larissa Jucá de Moraes Sales ${ }^{3}$
}

\footnotetext{
1 Doutorando em Sociologia pela Universidade Federal do Ceará. Professor de Ciências Sociais da Universidade Federal do Amapá Líder do Núcleo de Estudos em Política e Conflitos Sociais - NUPOCS/UNIFAP/CNPq e pesquisador do Laboratório de Estudos da Violência - LEV/UFC, Brasil.

E-mail: antonio.sabinoneto@yahoo.com (9) http://lattes.cnpq.br/1558255197212661 (iD http://orcid.org/0000-0003-4151-6508

2 Doutor em Sociologia, professor e pesquisador do Programa de Pós-Graduação em Sociologia (PPGS) e do Laboratório de Estudos da Violência (LEV) da Universidade Federal do Ceará (UFC), Brasil.

E-mail: leonardo sa@uol.com.br 1 http://lattes.cnpq.br/0430275226558223 iD http://orcid.org/0000-0001-5983-9132

3 Doutoranda em Sociologia pela Universidade Federal do Ceará. Pesquisadora do Laboratório de Estudos da Violência (LEV-UFC), Brasil.

E-mail: larissa.sales@gmail.com htp htp://lattes.cnpq.br/4504241803390083 (iD http://orcid.org/0000-0001-5456-1709
}

RESUMO: Este trabalho tem por objetivo analisar as estratégias utilizadas pelo Coronel Bezerra, exsecretário de Segurança Pública do Ceará, para conseguir a adesão do voto ao cargo de deputado estadual no pleito de 2014 no Ceará. Especificamente, pretendemos compreender como foram engendradas as práticas do referido candidato para ser caracterizado como representante da Segurança Pública; também é nosso objetivo lançar luzes sobre como foram acionadas as suas demais redes de pertencimento, com o intuito de criar novos vínculos com o campo político. Este esforço analítico se detém sobre dados etnográficos, vídeos publicados nas redes sociais e matérias vinculadas em jornais e blogs do estado do Ceará. É válido destacar que em seus discursos o Coronel Bezerra buscou associar-se à "legalidade", à defesa do "cidadão de bem" e à "luta contra a impunidade", tendo em vista que suas manifestações são permeadas por um forte teor moral, que visam à identificação com o cearense a partir de traços culturais compartilhados coletivamente.

Palavras-chave: Polícia Militar; Campanha eleitoral; Ceará.

'A voice against impunity' - An analysis about the election campaign of

Coronel Bezerra for the Ceará State Legislative Assembly

ABSTRACT: This paper aims to analyze the strategies deployed by Coronel Bezerra, a former secretary of Public Security in the state of Ceará, Brazil, to garner voters' support in the 2014 campaign to become member of the Ceará State Legislative Assembly. Specifically, we intended to understand the practices engendered by the candidate in order to be portrayed as a spokesperson of public security. It was also our goal to shed light on how other networks of belonging were activated in the perspective of fostering new social ties with the political field. This analytical endeavor ranged from ethnographical data, videos posted on social media, and articles of local newspapers and blogs. In his discourse, Coronel Bezerra sought to associate his image to the principle of 'legality', the defense of the 'good citizen', and the 'struggle against impunity'. His manifestations were charged by a strong moral tone, aiming to build a sense of identification with Ceará voters through collectively shared cultural traits.

Keywords: Military Police. Election campaign. Ceará. 


\section{INTRODUÇÃO}

"Uma voz contra a impunidade", este era o slogan de campanha do coronel Bezerra, então candidato a deputado estadual no ano de 2014. Vinculado à carreira Militar, Bezerra se destacou principalmente por seu capital político, por sua proximidade à família Ferreira Gomes, porém também se destacou pelas altas patentes que alcançou na PM cearense. Várias estratégias foram utilizadas para que sua candidatura se efetivasse, porém o que nos chama atenção foram as estratégias vinculadas aos campos de poder em que Bezerra transita.

Para nos ajudar nessa compreensão, retomamos Os usos sociais da ciência de Pierre Bourdieu. No texto o autor apresenta, a partir de uma análise sobre o campo científico, alguns de seus principais conceitos, através dos quais pretendemos ilustrar de forma mais fecunda no presente artigo. Ao explicar o que compreende como Campo, Bourdieu o caracteriza como um universo que engloba "os agentes e as instituições que produzem a arte, a literatura ou a ciência" (BOURDIEU, 2004, p. 20). Nomeadamente, é possível dizer que o Campo é o espaço legítimo das lutas pelo poder, pela honra ou pela notoriedade. É o local privilegiado onde ocorrem os embates pela legitimidade da verdade. Cada campo, diferenciado por suas singularidades, vincula-se aos demais a partir de um campo maior, o campo do poder, o qual engloba as estruturas específicas de todos os campos.

Aqui, objetivamos compreender como se relacionam as práticas articuladas dentro de um campo específico, o político. Para esta análise, enfocamos um agente em especial, que construiu a sua trajetória a partir do campo militar - o Coronel Bezerra. Elencar as estratégias empregadas pelo candidato ao cargo de deputado estadual cearense para a conquista da adesão do voto, ao ter em vista que esses dois campos possuem práticas agenciais distintas, constitui uma complexidade a ser debatida ulteriormente. É válido ressaltar que o campo político se organiza através de uma distribuição desigual dos meios de produção e de formação de opinião. Nesta relação, a política é costurada a partir da apropriação do poder, no qual os discursos produzidos por determinados agentes sociais estão envolvidos num emaranhado de acontecimentos que, a priori, são difíceis de elucidar. Tais agentes são, segundo Bourdieu (2011), os políticos profissionais que atuam cotidianamente na política, ao fazer desta sua vocação e sua razão de existência. Os políticos profissionais são aqueles que disputam com maior afinco os espaços de poder em detrimento aos "cidadãos comuns, reduzidos ao estatuto de consumidores, (que) devem escolher, com probabilidades de mal-entendidos tanto maiores quanto mais afastados estão do lugar de produção" (BOURDIEU, 2011. p.164).

Essas relações dentro do campo político se constituem a partir da ilusio (sentimento de estar e viver o jogo). Os agentes que incorporam as regras do jogo, através das estruturas do campo, têm a propensão de realizar suas práticas a partir de determinados posicionamentos, que são possíveis de desnaturalizar por meio da compreensão das engrenagens que põem esta mesma estrutura para funcionar. Essas engrenagens podem ser chamadas por habitus estruturas pré-conscientes inculcadas nos indivíduos - que reproduzem às práticas esperadas em determinado campo; ou seja, o habitus é o lócus de análise específico que 
gerencia as práticas a partir das estratégias possíveis do campo. É por meio dele que se cria/recria o sentido do jogo, que incorpora à pele as expectativas sobre as práticas dos agentes. Ao analisar especificamente o habitus político, Bourdieu (2011) o caracteriza como aquele que mais veementemente é possível afirmar que a sua formação não advém de práticas naturais. De forma singular, ele é:

“Em primeiro lugar, toda a aprendizagem necessária para adquirir o corpus de saberes específicos produzidos e acumulados pelo trabalho político dos profissionais do presente e do passado ou das capacidades mais gerais tais como o domínio de uma certa linguagem e de uma certa retórica política (...). Mas é também e sobretudo esta espécie de iniciação, com as suas provas e os seus ritos de passagem, que tendem a inculcar o domínio prático da lógica imanente do campo político e a impor uma submissão de facto aos valores, às hierarquias e às censuras inerentes a este campo ou à forma específica de que se revestem os seus constrangimentos e os seus controlos no seu de cada partido" (Bourdieu, 2011. p. 169-70)

Por meio das interfaces proporcionadas por Pierre Bourdieu e por outros autores que, de alguma forma foram influenciados por ele, é possível construir uma análise a partir das lutas existentes no campo da segurança pública quanto à sua influência sobre o campo político cearense. Para tanto, se faz necessário contextualizarmos o período político cearense em 2014.

\section{CAMPO POLÍTICO NO CEARÁ}

A relação entre segurança pública e eleições no Ceará não é um dado novo ${ }^{1}$. Con-

${ }^{1}$ Vide BARREIRA, 2004 e CARVALHO, 2005. tudo, no estado, investidas eleitorais de policias militares nunca foram alvo de grandes intervenções do Comando Geral, ao considerar que as candidaturas representavam atos isolados, de objetivos particulares ou, por vezes, ligados a grupos ${ }^{2}$ partidários hegemônicos na política estadual. Porém, no ano de 2011, é nítida a exacerbação dos conflitos no campo das disputas por legitimidade dentro da Polícia Militar, que levaram a cabo conflitos no campo político do estado. Nesse processo, dois grupos tomaram a dianteira nos embates pelo poder. $\mathrm{O}$ primeiro grupo, liderado pelo Governador Cid Gomes e seu irmão, o Ex-Governador Ciro Gomes; o segundo grupo, liderado por um Capitão da Polícia Militar, Wagner de Sousa, que se vinculou no pleito de 2014 ao grupo do senador Eunício Oliveira, candidato ao governo do Ceará. Esse dualismo propiciou uma disputa pela representação política, ao levar em consideração qual grupo proferia o discurso verdadeiro sobre a situação da segurança pública no Ceará.

Nas duas gestões em que governou o Ceará, entre 2007 e 2014, Cid Gomes propôs para a segurança pública uma reformulação a partir do discurso de modernidade, que estava centrado em uma reorganização do aparelho policial do Estado; contudo, tal posicionamento continuou a se enquadrar no modelo proposto pelo grupo que integrava ainda na década de $1990^{3}$; que se ca-

2 Quando cito grupo, estou pensando do mesmo modo em que Palmeira (1996) pensa as facções. Esse cita: "entre os antropólogos há um certo consenso de que se trata de unidades de conflito, cujos membros são arregimentados por um líder com base em princípios variados". (...) "são unidades de conflitos ativadas em ocasiões específicas antes do que mantidas por uma organização formal”. (PALMEIRA, 1996).

3 Grupo formado por empresários, 'filhos' de uma elite emergente que possuía frágil inserção política, que tinham por objetivo reformular a estrutura político-administrativa do Estado. Problematizaram o modelo vigente de governo, sempre lançando críticas diretas às formas tradicionais de poder dos 
racterizou a partir de práticas associadas à racionalização e à eficiência. Especificamente na área da segurança, tais práticas foram legitimadas por meio de um novo programa intitulado Ronda do Quarteirão, baseado na política de policiamento comunitário ${ }^{4}$. Este projeto procurou se diferenciar do modelo que há anos era encarado como "natural" na polícia cearense ${ }^{5}$. Pretenderam engajar uma série de inovações na estrutura de funcionamento e na forma de lidar com o problema da criminalidade, rompendo com práticas consideradas pela administração como coorporativas e desonestas.

Contudo, a PM cearense continuou a ser caracterizada como instituição hierárquica, cuja base de dominação se manteve diretamente ligada ao modelo pedagógico trabalhado por sua cúpula na formação dos quadros de oficiais e de praças. (SÁ, 2002). Este modelo de gestão do espaço coletivo continuou a garantir a corporação militar

atuais governantes. As críticas estavam embasadas no discurso de modernização que propunha a uma ruptura do 'passado' com o 'futuro', do 'atrasado' com o 'moderno' (BARREIRA, 2004), em que Tasso se constituía como figura central desse processo. Para Irlys Barreira (2000 p. 144), a reorganização do modelo político de Ceará está vinculada "a construção simbólica de uma temporalidade histórica, a associação entre as imagens do Estado e do governo efetivada na apresentação de um 'Ceará Moderno', e a sintonia entre princípios locais de administrar o poder."

${ }^{4}$ Rosemary Almeida (2011) caracteriza policiamento comunitário "como uma lógica em que a interação entre policiais e cidadãos comuns é uma exigência e uma necessidade. Compreende-se que fazer segurança no mundo atual é ter a capacidade de agir em pleno contato com o outro, de forma inteligente, madura, serena. Não é apenas mais um programa simpático da área de Segurança Pública. É uma Política de Segurança Pública, experimentada nos mais diferentes cantos do mundo, com formas inventadas e reinventadas de acordo com as características de cada lugar." (ALMEIDA, 2011:191).

${ }^{5}$ César Barreira (2004) confronta as práticas de gestão da segurança pública com o discurso de modernidade empregado no Ceará, a partir do Governo de Tasso Jereissati e Ciro Gomes. Destacando que a convocação de especialistas norte americanos, o novo perfil dos secretários de segurança pública, entre outras modificações, não obtiveram resultados expressivos no combate a violência no estado. um rígido controle hierárquico em sua estrutura. Nesta, os cabos e os soldados não têm o poder de comandar, exigindo-se destes uma postura disciplinar eminentemente de obediência as ordens superiores.

Nesse contexto, uma das principais estratégias de apropriação política, empregada pelo grupo do capitão Wagner - o único detentor de um capital político suficientemente consolidado a fazer frente ao grupo governista na área da segurança pública constituiu-se numa luta em busca por legitimação das bases dentro da corporação militar. Este grupo procurou desenvolver, por meio do discurso por reconhecimento ${ }^{6}$, a tentativa de atenuar os déficits nos espaços de poder dos praças, a fim de torná-los menos excludentes.

Esse contexto de lutas dentro do campo militar se refletiu no pleito de 2014 para as candidaturas aos cargos de governador e de deputados. O acirramento entre os dois grupos anteriormente citados proporcionou um longo embate discursivo, ancorado em acusações mútuas entre vários membros de cada facção. O principal exemplo está nas fortes tocas de acusações de cunho moral entre o capitão Wagner e o Governador Cid Gomes e seu irmão, o ex-governador Ciro Gomes durante o pleito eleitoral.

\section{A TRAJETÓRIA DE UM POLICIAL POLÍTICO}

Em sua apresentação numa rede social em 2014, Francisco Bezerra, 49, destaca que ingressou na Polícia Militar do Estado

\footnotetext{
${ }^{6} \mathrm{~A}$ busca por reconhecimento baseia-se na discussão em que Cardoso de Olivera (2002) faz sobre a categoria de Insulto Moral, que se enquadra em duas características. A primeira "trata-se de uma agressão objetiva a direitos que não pode ser adequadamente traduzida em evidências materiais" e a segunda "sempre implica uma desvalorização ou negação da identidade do outro" (CARDOSO DE OLIVEIRA, 2008).
} 
do Ceará como cadete, no Curso de Formação de Oficiais (CFO). Em sua trajetória, adquiriu os títulos de bacharel em segurança pública, além de duas pós-graduações e aperfeiçoamentos pelas academias de polícia de Brasília e do Ceará. Alcançou o posto de Coronel de polícia após ocupar vários cargos de comando em vários Batalhões do interior e da capital do estado; tendo a sua principal atuação no comando das "tropas de elite" da PM, dentre as quais se destacam os cargos de comandante do pelotão de controle de tumultos do BPCHOQUE, comandante do grupo ANTI-SEQUESTRO e comandante do Comando Tático Motorizado (COTAM).

Coronel Bezerra ocupou cargos de importância não apenas na administração interna da polícia, mas também foi nomeado ajudante de ordens do presidente da Assembleia Legislativa do Ceará, chefe da Casa Militar do governo do Ceará e ajudante de ordens do Governador do Ceará7. Essa apresentação realizada pelo policial demonstra o carácter central da "abordagem nas relações entre as características sociais e políticas que fundamentam a legitimação da candidatura e as suas vinculações com a ocupação de cargos políticos" (CORADINI, 2001). É válido ressaltar que esses últimos cargos estiveram ligados diretamente às gestões dos políticos da família Ferreira Gomes, especificamente aos que dependiam da nomeação de Cid Ferreira Gomes, enquanto Presidente da Assembleia Legislativa e Governador cearense. Assim, é possível observar que a trajetória de Bezerra

\footnotetext{
${ }^{7}$ A simples enumeração dos cargos ocupados na gestão pública se caracteriza no meio político, em muitos casos, como comprovação de experiência e de excelência do candidato como capacitado a ocupar outros cargos. Neste caso, aqueles de cunho eletivo. (CORADINI, 2001).
}

manteve-se vinculada a uma família que galgou espaços importantes na política estadual do Ceará; e que sua ascensão advém desta ter escolhido membros de seu próprio grupo, considerados leais e dignos de confiança, para cargos chaves na gestão do Estado. Foi a partir desse princípio, que envolvia a trajetória de experiência na Polícia e de confiança do Grupo Ferreira Gomes, que o Coronel Bezerra foi nomeado Secretário de Segurança Pública do Ceará8.

\section{GESTÃO COMO SECRETÁRIO DE SEGU- RANÇA}

Como Secretário de Segurança Pública, o coronel Bezerra se destacou como um dos principais defensores das políticas de segurança empregadas pelo Governo do Estado; tendo se constituído como o principal representante do discurso de defesa das ações engendradas pela pasta para enfrentar à criminalidade no Ceará. Pode-se notar em entrevista concedida ao jornal O Povo, ao ser indagado sobre o motivo de o Governo do Estado, mesmo após os altos investimentos na área da Segurança, não ter conseguido reduzir os números da criminalidade, o Secretário de Segurança respondeu, que:

Há seis anos, nós tínhamos 40 viaturas velhas circulando por Fortaleza, hoje, nós temos 250. Não havia concurso para a polícia, o governador, só na primeira gestão, incrementou

\footnotetext{
8 O jornal Diário do Nordeste relata em uma matéria os preparativos para a nomeação do Coronel Bezerra ao cargo de Secretário de Segurança Pública do Ceará. A matéria diz o seguinte "Em recente entrevista, o governador Cid Gomes declarou que colocaria um "pé de boi" na Secretaria de Segurança. Na linguagem "cidiana", "pé de boi" significa um servidor disciplinado e com força de trabalho. Uma solução caseira e com trajetória já bem conhecida pelo governador. É esse o perfil escolhido por Cid para a mais delicada e complexa das pastas estaduais." (Diário do Nordeste, 2010).
} 
a Polícia Militar com 4.085 novos policiais, além de 150 delegados e 250 escrivães. E já autorizou mais três mil policiais, 740 policiais civis, 270 bombeiros, 200 oficiais da Polícia Militar e 177 profissionais da Perícia Forense. Com todo esse investimento, a gente ainda vê o quanto a violência cresce, imagina se o governo tivesse ficado estático como outros governos. (O POVO, 2013).

Além das questões relacionadas ao aumento das taxas de criminalidade, anunciado pelas estatísticas produzidas pelo próprio Governo do Ceará, o então Secretário enfrentou problemas quanto à sua legitimação dentro das instituições policiais cearenses. Sua nomeação veio num momento em que ocorriam inúmeros conflitos nas forças de segurança pública locais, tendo em vista às reclamações dos praças da PM junto ao Governo do Estado, que culminaram na Greve de 2011 da Polícia Militar ${ }^{9}$, caracterizada como a principal crise da quebra de hierarquia (SILVA NETO, 2013) e de autoridade da Segurança Pública no estado.

A partir daí, a sua gestão enquanto Secretário concentrou forças para consolidar as ações do Batalhão de Choque da PM, em contraponto aos demais Batalhões, ao criar também o Comando Tático Rural ${ }^{10}$. Foi a

\footnotetext{
${ }^{9}$ A greve de 2011 da Polícia Militar do Ceará se constitui como um rico pano de fundo para se compreender como se configuram as relações de hierarquia, subordinação e autoridade entre os praças e os oficiais. Sua articulação, de início, foi orquestrada a partir das reclamações de graduados da corporação, que reivindicavam por consideração e por direitos dentro da instituição. Discursos de líderes, repletos de apelos emocionais, deflagraram um forte teor moral, constituindo-se como porta de entrada para que fosse demonstrado o descontentamento da tropa para com o Comando Geral da PM. Este contexto, repleto de conflitos, propiciou a consolidação de lideranças da Polícia Militar, que iniciaram forte oposição às ações do Secretário de Segurança Pública, do Governador Cid Gomes e de seu grupo.

10 Comando Tático Rural, o Cotar, a quinta companhia especializada do Batalhão de Polícia de Choque (BPCHoque).
}

partir desta configuração do campo e das práticas expostas pelos referidos agentes sociais que o coronel Bezerra iniciou a articulação de sua candidatura a cargo de deputado estadual.

\section{CANDIDATURA AO LEGISLATIVO NO CE- ARÁ}

Como principal defensor do modelo de gestão da Segurança Pública do governo Cid Gomes, Coronel Bezerra assume a tarefa de também ser o candidato de maior capital simbólico, com chances de vitória, a conquistar a adesão dos votos dos operadores da segurança pública e da "sociedade de bem" contra o Capitão Wagner. Após a sua exoneração do cargo de Secretário, Francisco Bezerra procurou delinear estratégias que reforçassem a sua trajetória como defensor da segurança pública, ao repercutir slogans associados à "legalidade", a "defesa do cidadão de bem" e a "luta contra a impunidade". Na mesma entrevista que havia concedido ao jornal O Povo, coronel Bezerra já dava a tônica de seus discursos em 2014, ao ressaltar que o trabalho da polícia não repercutia efetivamente devido às leis, que não constituíam um aparato de punição compatível com o necessário.

Nós temos uma demanda muito grande na área de repressão. O homicida que é preso já responde a um ou dois homicídios. Como que a lei permite que uma pessoa que mata outra seja colocada em liberdade? Como se justifica um adolescente confessar oito homicídios? Se ele tem oito registros de homicídios é porque a polícia já o prendeu oito vezes. A população tem de acordar para isso! A polícia está trabalhando. Mais de 23 mil pessoas foram presas em 2012 usando a estrutura que é destinada aos policiais para atuarem. (O Povo, 2013).

https://periodicos.unifap.br/index.php/estacao Macapá, v. 8, n. 2, p. 111-120, maio/ago. 2018 
Foi a partir da inserção de um habitus proveniente do campo militar no campo político que o coronel Bezerra construiu o seu discurso como representante da segurança. Numa carta redigida aos cearenses, o candidato expõe os motivos que lhe outorgaram como o indivíduo capaz de enfrentar a criminalidade, junto a isso acrescentou o porquê de ter escolhido se candidatar ao cargo de deputado estadual.

"Como ex-secretário da Segurança Pública do Ceará (...) tive a clara visão de que, entre muitos outros, um dos principais motivos do crescimento desenfreado da violência é a IMPUNIDADE ofertada aos criminosos, proporcionada pela decadência, ou podemos até dizer benevolência, das leis penais brasileiras. Como podemos aceitar que alguém que cometeu 1, 2, 5...10..e até 20 homicídios(caso concreto) continue em liberdade pelo simples fato de não ter completado, ainda, 18 anos de idade? Como imaginar que traficantes, assaltantes, sequestradores, estelionatários, depredadores, ladrões de automóveis e muitos mais que afligem a nossa sociedade, continuem em liberdade reincidindo de forma ainda mais grave contra a população, por reiteradas vezes? ISSO TEM QUE MUDAR...!!! TEMOS QUE LUTAR, TAMBÉM, PELOS DIREITOS DAQUELES QUE SÃO VÍTIMAS DA VIOLÊNCIA...!!! TEMOS QUE LUTAR PELO AGRAVAMENTO DAS PENAS DOS CRIMES QUE SÃO COMETIDOS CONTRA OS NOSSOS POLICIAIS...!!! Diante deste quadro é que me coloco à disposição do povo cearense para que na Assembléia Legislativa possa ser A VOZ DO POVO CEARENSE CONTRA A IMPUNIDADE!"(sic) (BEZERRA, 2014).

Na campanha, o coronel Bezerra passou a ser apresentado ao público como um homem sério, honesto e de bons costumes, ao construir a sua trajetória vinculada ao combate à impunidade como o principal mal da sociedade cearense. Como se pôde analisar, seus discursos passaram a ser respaldados pela crítica à maleabilidade das leis, que provocavam uma sensação de insegurança na população. Para o candidato, era inadmissível que a polícia continuasse prendendo os "bandidos", "assassinos" e "meliantes" enquanto a justiça continuasse a soltálos. Por tanto, resolveu ingressar na carreira política, com o intuito de mudar a legislação estadual, como a única forma de punir devidamente o bandido. Podemos depreender que o discurso do candidato retrata a criminalidade, a justiça e a sociedade a partir de uma linguagem contumaz do meio policial, em virtude de não podermos dissociar os discursos do referido coronel como candidato do local que ele ocupa no campo do poder.

Francisco Bezerra também fez questão de ressaltar a sua filiação ao grupo do Governador Cid Gomes. O blog do Roberto Moreira, no qual saíam recorrentes notícias exaltando os feitos e a campanha do Coronel, noticiou em abril de 2014 que através de sua influência foram conseguidas várias obras para o interior do Ceará, concomitante ao "apoio fechado de Cid Gomes".

Conseguiu com o governador Cid Gomes recursos para erguer o Portal de entrada de Canindé, uma sinalização importante para identificar as Romarias de São Francisco. O coronel Bezerra também conseguiu junto a secretaria de cidades intermediar a aprovação de um projeto para construção de 495 casas do Projeto Minha Casa Minha Vida. O coronel Bezerra é candidato a deputado estadual com o apoio fechado de Cid Gomes. (Blog do Roberto Campos, 2014).

No comitê de campanha do candidato, através do acesso a diálogos com assessores e com outros funcionários, pudemos 
vislumbrar o clima de vitória entre os presentes. Havia a expectativa de, no mínimo, 50 a 60 mil votos, demonstrado por meios e relações, este coeficiente seria auferido, com contas de imediato:

\footnotetext{
"o prefeito do município de Icó está conosco, então devemos obter em torno de 20 mil votos só nessa cidade. Existe um grupo que apoia o Coronel, o pessoal do som automotivo, que tem 80 mil pessoas, se $25 \%$ votarem nele já são mais 20 mil votos. Existe um grupo de empresários que também o apoia, ai tem os funcionários. Com um time desses a gente tira pelo menos 50 mil votos, por baixo" (Diário de campo)
}

Contudo, o Coronel Bezerra não conseguiu ser eleito, tendo alcançado quase 19 mil votos no pleito para o cargo de Deputado Estadual. Alguns pontos podem ser elencados para se compreender o porquê do resultado.

\section{CONSIDERAÇÕES FINAIS}

Como dito anteriormente, houve uma série de estratégias discursivas usadas pelo Coronel Bezerra para sua inserção nesse campo de poder. O manejo de seu capital político sempre acionados nos discursos não garantiu que fosse eleito como deputado estadual, menos ainda a tentativa de construção de uma reputação baseada em sua ascensão profissional, onde o prestígio é uma potente arma de impulso político.

Ainda que buscasse evidenciar seu capital político, pôde ser constatado que em nenhum veículo de imprensa nem nas páginas das redes sociais vinculadas à campanha do candidato, foi divulgada alguma referência, discurso, nota ou similar do apoio de Cid Gomes ao seu principal candidato, representante da segurança pública ao cargo de deputado estadual. Afinal, Bezerra demonstrava possuir um capital político acumulado por delegação, transferido pelo líder do grupo para a sua pessoa. Contudo, a omissão do então Governador pelo seu ex-secretário de segurança pública refletiu numa candidatura que destoava da presença e influência necessárias para a eleição.

Diferente do que aconteceu com o coronel Bezerra, o candidato com quem ele concorria diretamente pelo mesmo troféu da representação, desempenhou um papel preponderante junto ao seu candidato a Governador do Ceará. Capitão Wagner aparecia semanalmente no horário eleitoral de Eunício Oliveira, debatendo a temática da segurança em nome do candidato ao governo. Já o Coronel Bezerra não foi citado, em nenhum momento, pelo candidato ao governo do Ceará, Camilo Santana.

As ações divulgadas pela mídia sobre a pasta da segurança pública, quando se referiam à época que o coronel Bezerra era o secretário, não o citavam em nenhum momento. Como, então, Bezerra poderia se credenciar como ex-secretário de segurança pública e coronel da polícia militar, se o grupo que representava não o punha como aquele que trabalhou para resolver o problema da criminalidade perante os eleitores? Desta maneira, Bezerra passou despercebido entre os holofotes da disputa estadual. E não apareceram as realizações que ele destacava como sendo de sua autoria.

Outro ponto importante é perceber a força política do novo representante da polícia militar, que por força do capital político adquirido durante os movimentos de contestação e a criação de uma imagem de "igualdade parcial" entre oficiais e praças, distanciando aquela imagem militarizada da 
hierarquia da caserna, Capitão Wagner conseguiu ser eleito com folga, em contraposição a uma campanha pouco visada como a de Coronel Bezerra.

Este cenário traz à tona as novas roupagens que este campo político vem ganhando e como se constitui o novo processo de luta por legitimidade, não mais pautada pelos valores consolidados de hierarquia e disciplina que a figura de um Coronel na PM transparece. Traz para o debate a emergência de novas figuras neste campo e como estão sendo mobilizados os interesses de votação e o modo como essas figuras aparecem na mídia. Tais fatos nos dão pistas para seguir nossos focos de estudo.

\section{REFERÊNCIAS}

ALMEIDA, R. Cidadania e Policiamento Comunitário. In: BARREIRA, C. BATISTA, E. (In)Segurança e Sociedade: treze lições. Campinas-SP: Pontes Editores. 2011. p. 191208.

BARREIRA, C. Em nome da lei e da ordem: a propósito da política de segurança pública. São Paulo Perspec., v. 18 n. 1. São Paulo, jan./mar. 2004.

- Questão de segurança: políticas governamentais e práticas policiais. Rio de Janeiro: Relume Dumará: Núcleo de Antropologia da Política, 2004.

BARREIRA, I. A. F. Pensamentos, Palavras e Obras: As bases de legitimação do Governo de Tasso Jereissati. In: HEREDIA, Beatriz M. A. (org.) Continuidades e rupturas na política cearense. Campinas-SP: Pontes Editores, 2008.

BOURDIEU, P. O Poder Simbólico; tradução Fernando Tomaz. 15. ed. Rio de Janeiro; Bertrand Brasil, 2011.

. Os usos sociais da ciência: por uma sociologia clínica do campo científico; tradução Denice Barbara Catani. - São Paulo: Editora UNESP, 2004.

Razões Práticas: Sobre a teoria da ação. Tradução: Mariza Corrêa. 11. ed. Campinas, SP. Papirus, 2011.

CARVALHO, J. M. Forças Armadas e política no Brasil. 2. ed. Rio de Janeiro: Jorge Zahar Editor, 2006.

CORADINI, O. Em nome de quem: recursos sociais no recrutamento de elites políticas Rio de Janeiro: Relume Dumará: UFRJ, Núcleo de Antropologia da Política, 2001.

OLIVEIRA, L. R. C. Existe Violência sem Agressão Moral? Revista Brasileira de Ciências Sociais, São Paulo, v. 23 , n. 76, p. 136146, jun. 2008.

PALMEIRA, M. Política, Facções e Voto. In: PALMEIRA, Moacir e GOLDMAN, Márcio. (Org.s). Antropologia, Voto e Representação Política. Rio de Janeiro: Contra Capa Livraria, 1996.

SÁ, L. Os Filhos do Estado: auto-imagem e disciplina na formação dos oficiais da Polícia Militar do Ceará. Rio de Janeiro: Relume Dumará: Núcleo de Antropologia Política/UFRJ. 2002. (Coleção Antropologia Política: 15)

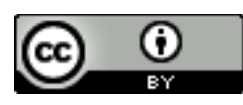

License information: This is an openaccess article distributed under the terms of the Creative Commons Attribution License, which permits unrestricted use, distribution, and reproduction in any medium, provided the original work is properly cited.

Artigo recebido em 16 de fevereiro de 2019.

Avaliado em 18 de fevereiro de 2019.

Aceito em 19 de fevereiro de 2019.

Publicado em 28 de fevereiro de 2019.

\section{Como citar este artigo (ABNT):}

SILVA NETO, Antonio Sabino da; SÁ, Leonardo Damasceno de; SALES, Larissa Jucá de 
Moraes. "Uma voz contra a impunidade": uma análise sobre o contexto da campanha eleitoral do Coronel Bezerra à Assembleia Legislativa do Ceará. Estação Científica (UNIFAP), Macapá, v. 8, n. 2, p. 111-120, maio/ago. 2018. 